\title{
Subregional Hippocampal Thickness Abnormalities in Older Adults with a History of Heavy Cannabis Use
}

Alison C. Burggren, ${ }^{1,2, *}$ Prabha Siddarth, ${ }^{1}$ Zanjbeel Mahmood, ${ }^{3}$ Edythe D. London, ${ }^{1,4}$ Theresa M. Harrison, ${ }^{5}$ David A. Merrill, ${ }^{1}$ Gary W. Small, ${ }^{1}$ and Susan Y. Bookheimer ${ }^{1,2}$

\begin{abstract}
Background and Aims: Legalization of cannabis (CB) for both medicinal and, in some states, recreational use, has given rise to increasing usage rates across the country. Of particular concern are indications that frequent $C B$ use may be selectively harmful to the developing adolescent brain compared with adult-onset usage. However, the long-term effects of heavy, adolescent CB use on brain structure and cognitive performance in late-life remain unknown. A critical brain region is the hippocampus $(\mathrm{HC})$, where there is a striking intersection between high concentrations of cannabinoid 1 (CB1) receptors and age-related pathology.

Design: We investigated whether older adults (average age $=66.6+7.2$ years old) with a history of early life CB use show morphological differences in hippocampal subregions compared with older, nonusers.

Methods: We performed high-resolution magnetic resonance imaging combined with computational techniques to assess cortical thickness of the medial temporal lobe, neuropsychological testing, and extensive drug use histories on 50 subjects (24 formerly heavy cannabis users [CB+ group] abstinent for an average of 28.7 years, 26 nonusers [CB- group]). We investigated group differences in hippocampal subregions, controlling for age, sex, and intelligence (as measured by the Wechsler Test of Adult Reading), years of education, and cigarette use.

Results: The CB+ subjects exhibited thinner cortices in subfields cornu ammonis 1 [CA1; $F(1,42)=9.96, p=0.0003$, and $C A 2,3$, and the dentate gyrus [CA23DG; $F(1,42)=23.17, p<0.0001$ ], and in the entire HC averaged over all subregions $[\mathrm{F}(1,42)=8.49, p=0.006]$.

Conclusions: Negative effects of chronic adolescent CB use on hippocampal structure are maintained well into late life. Because hippocampal cortical loss underlies and exacerbates age-related cognitive decline, these findings have profound implications for aging adults with a history of early life usage.

Clinical Trial Registration: ClinicalTrials.gov \# NCT01874886.
\end{abstract}

Keywords: hippocampus; magnetic resonance imaging; high-resolution; cortical thickness

\section{Introduction}

Marijuana (Cannabis sativa) is the most widely used "illicit" drug worldwide, with an estimated 183 million past-year users worldwide, ${ }^{1}$ over 20 million Americans reporting previous month use, and 4.6 million Ameri- cans meeting criteria for dependence in 2015 . $^{2}$ Adolescent cannabis $(\mathrm{CB})$ use is particularly concerning given the vulnerability of the adolescent brain. ${ }^{3}$ Since brain development continues throughout young adulthood, ${ }^{4}$ adolescence may be a critical period during which $\mathrm{CB}$

\footnotetext{
${ }^{1}$ Semel Institute for Neuroscience and Human Behavior, University of California, Los Angeles, California.

${ }^{2}$ Center for Cognitive Neurosciences, University of California, Los Angeles, California.

${ }^{3}$ San Diego Joint Doctoral Program in Clinical Psychology, San Diego State University/University of California, San Diego, California.

${ }^{4}$ Department of Molecular and Medical Pharmacology, University of California, Los Angeles, California.

${ }^{5}$ Helen Wills Neuroscience Institute, University of California, Berkeley, California.
}

*Address correspondence to: Alison C. Burggren, PhD, Semel Institute of Neuroscience and Human Behavior, University of California, Los Angeles, 760 Westwood Plaza 27-370B, Los Angeles, CA 90095-1759, E-mail: aclement@ucla.edu

(C) Alison C. Burggren et al. 2018; Published by Mary Ann Liebert, Inc. This Open Access article is distributed under the terms of the Creative Commons License (http://creativecommons.org/licenses/by/4.0), which permits unrestricted use, distribution, and reproduction in any medium, provided the original work is properly cited. 
exposure may have long-lasting implications. ${ }^{5}$ In animal models, the primary psychoactive ingredient in $\mathrm{CB}, \Delta$ 9-tetrahydrocannabinol (THC) induces dosedependent neurotoxic changes in the brain. ${ }^{6,7}$ Specific brain regions affected, including the hippocampus (HC), amygdala, striatum, and cingulate cortex, have high densities of cannabinoid 1 (CB1) receptors ${ }^{8}$ and, importantly, are among the first brain areas to show age-related morphological changes. ${ }^{9}$

For several decades, results regarding whether chronic $\mathrm{CB}$ use damages the brain were mixed. ${ }^{10-13}$ However, technological advances in magnetic resonance imaging (MRI) have enabled findings that chronic CB use has a significant effect on hippocampal structure in adolescents, ${ }^{5,14-17}$ and mounting evidence points to cognitive impairment after heavy CB use. ${ }^{18-21}$ People who were adolescents in the 1960s and 70s, when CB use doubled, ${ }^{22}$ are now entering late life, a period of high risk for age-related memory and cognitive deficits. ${ }^{23-27}$ However, how heavy CB use early in life affects brain structure and cognitive performance in late life is unknown.

We focused the present investigation on hippocampal morphology and cognitive performance because the $\mathrm{HC}$ exhibits dense concentrations of CB1 receptors ${ }^{8,28}$ and because it is the primary site of age-related changes associated with memory impairment and dementia. ${ }^{23,24,29}$ Prior MRI studies have suggested a particularly adverse effect of $\mathrm{CB}$ on the $\mathrm{HC}$ during adolescent brain development. ${ }^{14}$ There is also substantial evidence for neuroanatomical abnormalities within the $\mathrm{HC}$ in $\mathrm{CB}$ users. ${ }^{30-32}$

One study of heavy CB users found smaller volumes of the $\mathrm{HC}$ and amygdala, and provided some of the earliest imaging evidence that heavy, long-term CB use is harmful to brain tissue. ${ }^{33}$ In younger subjects (30 years on average), volumes in hippocampal subregions CA1, 2,3 and the dentate gyrus (DG) were smaller in dependent $\mathrm{CB}$ users than in nonusers, ${ }^{30}$ but similar data were not available from older subjects (over the age of 55) to see whether changes to hippocampal structure persisted over time.

In this study, ultra-high-resolution MRI data focusing on the $\mathrm{HC}$ were obtained and analyzed using a cortical unfolding technique, enabling analysis of cortical thickness in hippocampal subregions. This technique has been used to reveal subtle brain differences among cognitively intact older adults, ${ }^{34-36}$ to predict decline in cognition, ${ }^{37}$ and to show changes in the CA1 in multiple sclerosis. ${ }^{38}$

Subregional analysis of the HC has been shown in other laboratories, ${ }^{39}$ and ours, ${ }^{34}$ to be more sensitive to subtle morphological differences in hippocampal subregions than volumetric analyses. Additionally, CB1 receptors are not distributed equally across the $\mathrm{HC}$ but are most densely concentrated in CA2, CA3, and the DG, followed by CA1 in decreasing order. ${ }^{40}$ Similarly, cortical thinning in aging is region specific, with entorhinal cortex (ERC) and CA1 particularly affected. ${ }^{41}$

As a control to show that brain differences are specific to regions with high $\mathrm{CB} 1$ receptor density, we also conducted a region of interest (ROI) analysis of the parietal cortex, a brain region which also exhibits age-related morphological changes in late life, but which has a lower $\mathrm{CB} 1$ receptor density than the medial temporal lobe (MTL). ${ }^{42}$ Hippocampal and parietal cortex morphology were therefore compared between former heavy $\mathrm{CB}$ users ("CB + " group) and control subjects ("CB-" group). This is the first study that examines older individuals with a history of early life $\mathrm{CB}$ use to answer questions about the longitudinal effects of $\mathrm{CB}$ use in the aging brain.

\section{Methods}

The study was conducted with the approval of the UCLA IRB; subjects were recruited from the local community through advertisements in local media resources and signed informed consent forms before participating. Subjects were first screened over the phone and those reporting use of cocaine, methamphetamine, ecstasy, heroin, or other illicit substances more than once were excluded. We recruited older subjects (5775 years old) with "significant" CB exposure during adolescence (defined as CB use on at least 20 days/month, initiating use during adolescence (before age 20) and continuing for at least 1 year with no more than one to two uses/month after age 35).

We enrolled 24 former heavy $\mathrm{CB}$ users ("CB + ") and 26 control subjects (" $\mathrm{CB}-$ ") who reported never having used cannabis or any other illicit substances. Participants also provided a urine sample for biological verification of abstinence from use of any illicit substances on the day of neuropsychological testing (Instant-View MultiDrugs of Abuse Urine Test; Alfa Scientific Designs, Inc.). Participants with a history of neurological or psychiatric disorders, engagement in psychological treatment (within the previous 6 months), or current or past diagnoses of psychotic disorders were excluded from the study using DSM-V criteria. ${ }^{43}$

During their visit, participants underwent neuropsychological testing, a clinical interview, a physical and 
medical examination, and laboratory screening, including tests to rule out medical conditions that could affect cognitive performance (e.g., abnormal thyroid or pituitary hormone levels). ${ }^{44,45}$ Subjects with a history of uncontrolled hypertension or cardiovascular disease (systolic blood pressure $[\mathrm{BP}]>170$ or diastolic $\mathrm{BP}$ $>100$ ), head trauma, or other major systemic disease affecting brain function were excluded. Participants taking medications that could influence psychometric testing were also excluded. ${ }^{46}$ Drug use characteristics were assessed through a semistructured interview ("Drug Use History;" Table 1), which was used to characterize lifetime and current substance use.

Participants' self-reported substance use was further corroborated with an additional measure of substance use (Timeline Follow Back $[\text { TLFB }]^{47}$ ). Subjects were also given the Hollingshead Four-Factor Index of Socioeconomic Status ${ }^{48}$ to assess the influence of socioeconomic status (SES). Additionally, subjects were given the Mini-Mental State Examination to assess cognitive state, ${ }^{49}$ the Hamilton-D rating scale to assess depression, ${ }^{50}$ and the Wechsler Test of Adult Reading (WTAR) to estimate premorbid intellectual functioning. ${ }^{51}$ Based on the high co-occurrence of $\mathrm{CB}$ use with cigarette smoking and alcohol use, smoking and light alcohol use ( $<14$ drinks/week for men, $<7$ drinks/ week for women) were allowed.

Results from the Marijuana Smoking History Questionnaire (MSHQ) ${ }^{52}$ were used to create variables of interest related to $\mathrm{CB}$ use, including "Age of Onset" and "Lifetime Marijuana Use" (Average use/week $\times$ Number of years of use). We investigated the relationship between these variables in $\mathrm{CB}+$ and $\mathrm{CB}$ - subjects and MTL subregional thickness. As frequency may be different over time (i.e., $5 \times /$ year for 2 years, then $1 \times /$ year for 25 years), the Lifetime Marijuana Use composite score was chosen as the most accurate representation of usage over many years.

We divided neuropsychiatric test scores into the following domains of cognitive function: Memory Encoding, Delayed Memory, Processing Speed, and Executive Functioning (see Fig. 4 for individual tests in each domain). Studies using these domains have been reported elsewhere. ${ }^{37,53-55}$ Raw scores in each test were first converted to $Z$ scores $[Z=$ (raw score-mean)/standard deviation] and then binned together to create a domain $\mathrm{Z}$ score by averaging the $\mathrm{Z}$ scores belonging to the cognitive tests in each domain.

All participants underwent a $45-\mathrm{min}$ scan at the $3 \mathrm{~T}$ Siemens Trio scanner located in the Center for Cognitive Neuroscience at the Semel Neuropsychiatric Institute using a 12-channel parallel coil. After scout and localizer scans were acquired ( $2 \mathrm{~min}$ ), high-resolution fast spin echo (FSE) scans of the HC were acquired in an oblique coronal plane perpendicular to the long axis of the $\mathrm{HC}$ to ensure complete coverage (see Fig. 1a; FSE, repetition time $[\mathrm{TR}]=4800 \mathrm{~ms}$, echo time $[\mathrm{TE}]=$ $106 \mathrm{~ms}$, field of view [FOV] 150, 512×512, NEX4, 26

Table 1. Drug Abuse Phenotyping (1 h)

\begin{tabular}{|c|c|c|c|c|}
\hline Measure & Description & Variables & Duration & $\begin{array}{l}\text { No. of } \\
\text { Items }\end{array}$ \\
\hline $\begin{array}{l}\text { Fagerstrom Test for Nicotine } \\
\text { Dependence }\end{array}$ & $\begin{array}{l}\text { Self-report assessment (six items) of smoking behavior } \\
\text { (e.g., time to first cig, cigs/day) and dependence. }\end{array}$ & $\begin{array}{l}\text { Smoking behavior, } \\
\text { nicotine dependence }\end{array}$ & $\begin{array}{l}\sim 3 \text { min Smokers } \\
\text { only }\end{array}$ & 12 \\
\hline $\begin{array}{l}\text { Cigarette Use Timeline } \\
\text { (London Lab, unpublished) }\end{array}$ & $\begin{array}{l}\text { Self-report form. Participant to fill in smoking rates } \\
\text { on a timeline of his/her smoking history. } \\
\text { Used to estimate pack-years. }\end{array}$ & $\begin{array}{l}\text { Cigarettes/day over } \\
\text { the smoking history }\end{array}$ & $\begin{array}{l}5-10 \text { min Smokers } \\
\text { only }\end{array}$ & $\mathrm{N} / \mathrm{A}$ \\
\hline $\begin{array}{l}\text { Drug Use History } \\
\text { (London Lab, unpublished) }\end{array}$ & $\begin{array}{l}\text { Structured interview utilizing a standard form. } \\
\text { Collects data regarding use of drugs of abuse in all } \\
\text { classes (age at first use, current usage, greatest } \\
\text { regular lifetime usage, and peak usage). }\end{array}$ & $\begin{array}{l}\text { Complete drug } \\
\text { use history }\end{array}$ & $15 \min$ & 1011 \\
\hline $\begin{array}{l}\text { Marijuana Dependence } \\
\text { Checklist }^{71}\end{array}$ & $\begin{array}{l}\text { Self-report questionnaire. Items assess dependence } \\
\text { on cannabis. }\end{array}$ & Cannabis dependence & $\begin{array}{l}\text { 2-3 min MJ smoker } \\
\text { only }\end{array}$ & 10 \\
\hline $\begin{array}{l}\text { Marijuana Smoking History } \\
\text { Questionnaire }\end{array}$ & $\begin{array}{l}\text { Self-report questionnaire. Collects data regarding } \\
\text { recent and lifetime cannabis use, average amounts } \\
\text { of use and routes of administration. Also asks about } \\
\text { changes in use, and quit attempts. }\end{array}$ & Cannabis use & $1-8 \mathrm{~min}$ & 22 \\
\hline $\begin{array}{l}\text { Smoking History Questionnaire } \\
\text { (London Lab, unpublished) }\end{array}$ & $\begin{array}{l}\text { Self-report form. Items relate to benchmarks of } \\
\text { smoking behavior (e.g., age at first cigarette, age } \\
\text { at first } 100 \text { cigarettes, longest quit attempt, number } \\
\text { of quit attempts, reasons for quitting) }\end{array}$ & $\begin{array}{l}\text { Data related to } \\
\text { smoking behavior }\end{array}$ & $5 \min$ & 26 \\
\hline Timeline-Followback Interview ${ }^{47}$ & $\begin{array}{l}\text { Interview using memory prompts to determine } \\
\text { substance use for the last } 30 \text { days. }\end{array}$ & Alcohol Use & $15 \min$ & 30 \\
\hline
\end{tabular}

Testing battery used for assessing drug use history for individual subjects. Individual test names are listed along with a description of the test, the variables tested for, and the duration of the test. 
slices, $2 \mathrm{~mm}$ thick, $0 \mathrm{~mm}$ spacing, $400 \times 400 \mu \mathrm{m}$ in-plane resolution). This sequence optimizes in-plane resolution, where the subregional variability is largest, while producing minimal variability through plane when the slices are precisely perpendicular to the long axis. We also acquired a Magnetization-Prepared Rapid Acquisition Gradient Echo (MPRage) scan for excellent gray-white contrast (T1-weighted volumetric study: TR 2300; TE: 2.93; flip angle $8^{\circ}$; FOV $256 \times 256$; bandwidth $210 \mathrm{~Hz} /$ px; 1-mm isotropic voxels) for visual reference during segmentation and ROI analyses.
We used cortical unfolding to improve visualization of the convoluted MTL cortex by flattening the entire three-dimensional volume into a two-dimensional flat map. ${ }^{34,35,56}$ Methods for high-resolution hippocampal analysis with unfolding are described in detail elsewhere. ${ }^{35}$ Boundary demarcations divided the following subregions encompassed by gray matter: cornu ammonis (CA) fields 1,2 , and 3, the DG, subiculum (Sub), ERC, perirhinal cortex, parahippocampal cortex, and the fusiform gyrus (Fus) (Fig. 1b-e). This strip of gray matter is used as the input for the unfolding
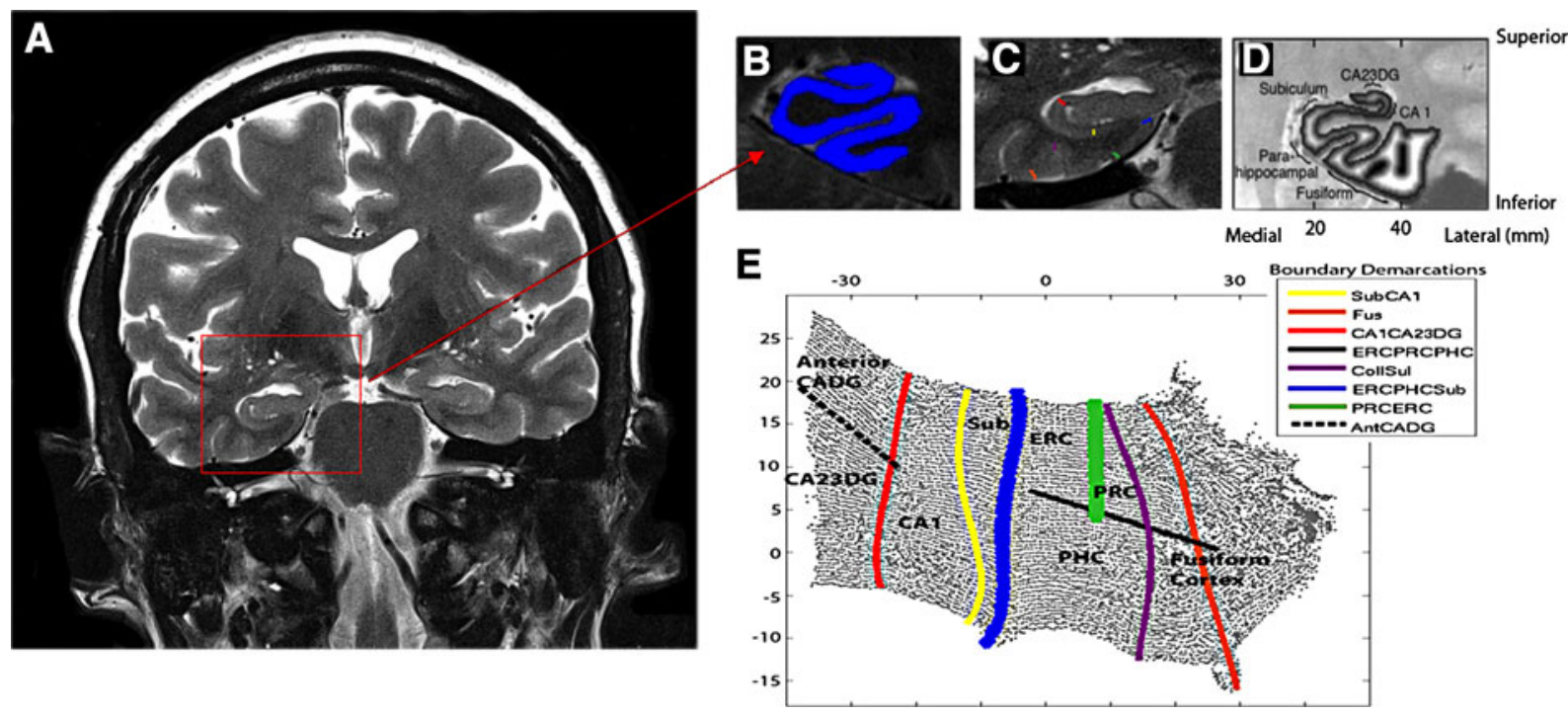

FIG. 1. High-resolution hippocampal image processing and thickness calculations. (A) The goal of highresolution hippocampal image processing is to isolate the strip of gray matter in the MTL that encompasses the subregions of the hippocampus proper and surrounding neocortex, shown in (B) in blue. This is done by manually segmenting cerebrospinal fluid and white matter and growing sequential layers of gray matter from the edge of white matter until the layer reach the cerebrospinal fluid boundary. (C) The boundaries between MTL subregions are marked according to anatomical landmarks. Because of limits in resolution in CA fields 2, 3, and DG we treat these regions as a single entity (CA23DG). Demarcations shown here include CA fields 2, 3, and the dentate gyrus (CA23DG) | CA1 (red), CA1 | subiculum (Sub; yellow), PHC | Sub (blue), fusiform gyrus (Fus; orange), Collateral sulcus (CollSul; purple) and PRC (green). (D) Boundary delineations were projected to their corresponding coordinates in flat map space. Each subregion is considered separately for cortical thickness calculations. Cortical thickness is visualized in in-plane space as a grayscale map of thickness values between maximum (white) and minimum (black) values. (E) To extract thickness, the distance from each voxel in inplane space to the nearest nongray matter voxel was calculated. Next, the maximum distance value of twodimensional voxels for the corresponding three-dimensional voxels across all layers was taken and multiplied by two to calculate mean thickness. Demarcations were projected from in-plane space to the corresponding location in 2D flat map space and then extended to form complete and smooth boundaries between subregions. CA1, cornu ammonis 1; ERC, entorhinal cortex; PHC, parahippocampal cortex; PRC, perirhinal cortex; MTL, medial temporal lobe. 
procedure, an iterative algorithm based on multidimensional scaling (http://ccn.ucla.edu/wiki/index.php /Unfolding). Cortical thickness within subregions was averaged over both hemispheres. The following formula was used to normalize hippocampal thickness values to intracranial volume (ICV) estimates: ICV-corrected thickness $=\left[\left(\right.\right.$ thickness in $\mathrm{mm} / \mathrm{ICV}$ in $\left.\left.\mathrm{mm}^{3}\right) \times 10^{6}\right]$. Multiplying by $10^{6}$ results in values at the same order of magnitude as original thickness estimates.

We used FreeSurfer 6.0 to process T1 MRI scans (http://surfer.nmr.mgh.harvard.edu). Based on the statistical maps from the data set, The Open Access Series of Imaging Studies (OASIS; https://www.oasis-brains .org), we created an ROI of parietal cortex. For volumetric calculations of volume in inferior parietal lobe, we used FreeSurfer on whole brain T1-weighted scans. After the automated portion of the FreeSurfer pipeline was complete, each participant's scan was visually checked for accuracy. Minimal manual edits were completed by a single individual when necessary. ICV values from FreeSurfer were used to normalize volume in the parietal lobe volumes. Because FreeSurfer parcellation results in separate volumes for superior and inferior parietal lobe volumes, results from the two ROIs were used to create an average parietal lobe ROI for each subject.

\section{Statistical analyses}

Demographic variables between groups were compared using $t$-tests for continuous measures and chi-squared tests for categorical measures. General linear models were used to test for significant group differences in thickness for each of the MTL subregions, with sex, age, WTAR, cigarette use, and education included as covariates. Differences in neuropsychological performance in each domain were also tested with general linear models, with the same covariates shown above. A similar model examined differences in the volumes of parietal lobes between $\mathrm{CB}+$ and $\mathrm{CB}-$ groups, controlling for the above covariates as well as total ICV. In addition to the standard statistics, we also present effect sizes (ES; Cohen's d) for all group differences. Statistical significance was set at $p=0.05$ for all models.

\section{Results}

Clinical and demographic characteristics are described in Table 2. Results from the MSHQ (Table 1) indicated an average age of onset of $17.7 \pm 4.2$ years of age and lifetime cannabis use of $11.3 \pm 13.0$ years duration. Groups did not differ in age, gender, or MMSE scores. However, the groups differed in number of years of education, cigarette usage, and WTAR performance; these variables were included as covariates in general linear models examining differences in the mean between the two groups.

$\mathrm{CB}+$ subjects had thinner cortex in subfields CA1 $[\mathrm{F}(1,42)=9.96, p=0.003 ; \mathrm{ES}=0.98]$ and $\mathrm{CA} 23 \mathrm{DG}$ $[\mathrm{F}(1,42)=23.17, p<0.0001 ; \mathrm{ES}=1.49]$ (Fig. 2) and thinner $\mathrm{HC}$ averaged over all subregions $[\mathrm{F}(1,42)=$ 8.49, $p=0.006$; ES=0.90] (Fig. 3). WTAR scores were significantly lower in $\mathrm{CB}+$ subjects $[t(47)=2.24$, $p=0.03$ ], but even after removing the most extreme values in WTAR (to better match groups on WTAR performance and ensure that this factor was not

Table 2. Demographic and Clinical Characteristics of Study Participants (mean/n \pm SD)

\begin{tabular}{|c|c|c|c|}
\hline & $\mathrm{CB}+$ & $\mathrm{CB}-$ & Between-group statistics \\
\hline Cohort characteristics & $n=24$ & $n=26$ & $t(48) / \chi^{2}(1), p$-value \\
\hline Mini-Mental State Examination score & $28.0 \pm 1.6$ & $28.4 \pm 1.7$ & $0.82,0.42$ \\
\hline Age, years & $65.4 \pm 7.2$ & $67.7 \pm 7.1$ & $1.12,0.27$ \\
\hline Educational achievement, years & $15.3 \pm 2.0$ & $16.6 \pm 2.3$ & $2.04,0.05^{* *}$ \\
\hline Female sex, $n(\%)$ & $8(33)$ & $12(46)$ & $1.92,0.17$ \\
\hline Cigarette smoker, $n(\%)$ & $14(58)$ & $7(27)$ & $5.05,0.02^{* *}$ \\
\hline Hamilton Depression Scale score & $7.0 \pm 7.5$ & $4.9 \pm 5.3$ & $1.16,0.25$ \\
\hline WTAR & $35.7 \pm 9.6$ & $41.2 \pm 7.4$ & $2.24,0.03^{* *}$ \\
\hline Hollingshead coding & $5.4 \pm 1.7$ & $5.8 \pm 1.7$ & $0.92,0.36$ \\
\hline Cannabis use & & - & - \\
\hline Onset of regular use (age in years $\pm S D$ ) & $17.7 \pm 4.2$ & - & - \\
\hline Duration of use (years $\pm S D$ ) & $11.3 \pm 13.0$ & - & - \\
\hline Lifetime use (days $\pm S D)$ & $4181.2 \pm 4784.6$ & - & - \\
\hline Length of abstinence (years $\pm S D$ ) & $29.9 \pm 6.0$ & - & - \\
\hline Lifetime alcohol use (no. of standard drinks/month \pm SD) & $21.6 \pm 12.0$ & $19.8 \pm 11.3$ & $-0.54,0.59$ \\
\hline
\end{tabular}

${ }^{* *} p<0.05$.

SD, standard deviation; WTAR, Wechsler Test of Adult Reading. 


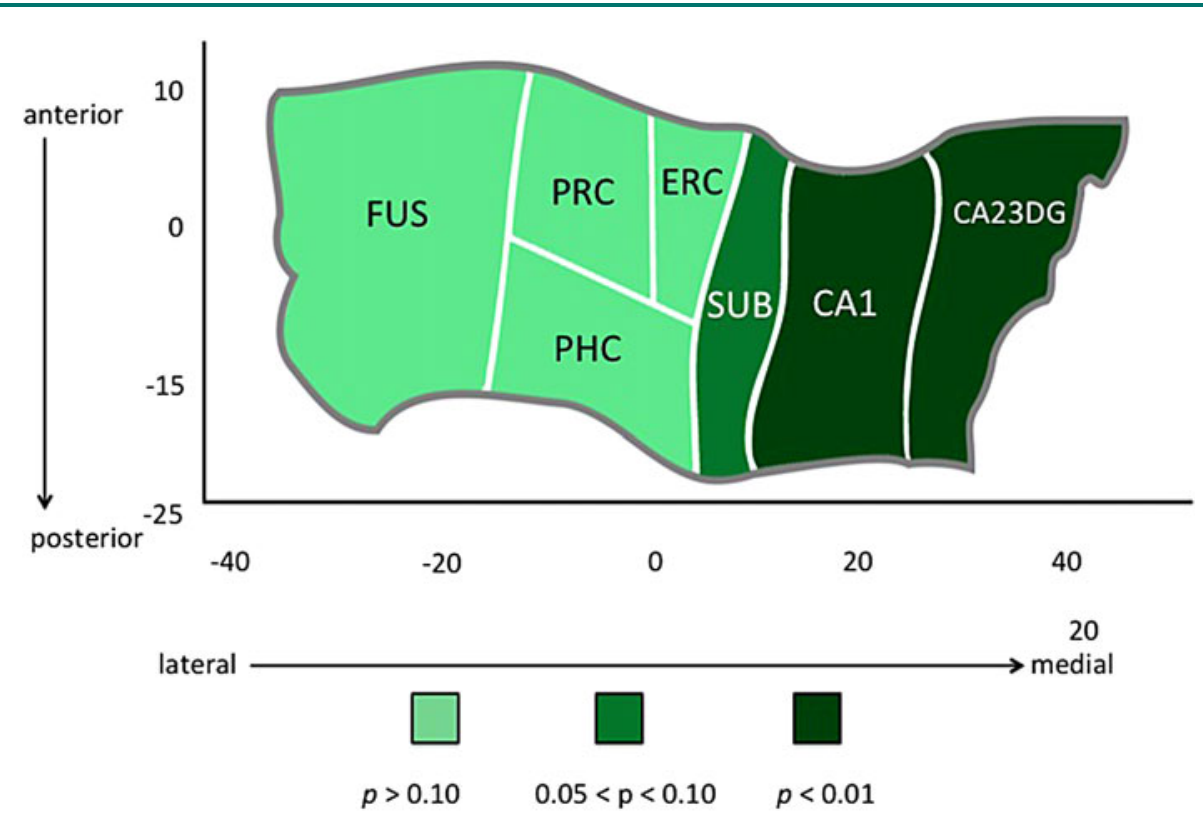

FIG. 2. Hippocampal complex unfolding reveals relationship between $C B$ use and subregional hippocampal morphology in late life. A cortical unfolding procedure was used to produce a flat map of the hippocampal complex. Regions are color coded according to the strength of the statistical association between CB group and cortical thickness in individual subregions within the hippocampus and surrounding neocortex. $\mathrm{CB}$, cannabis.

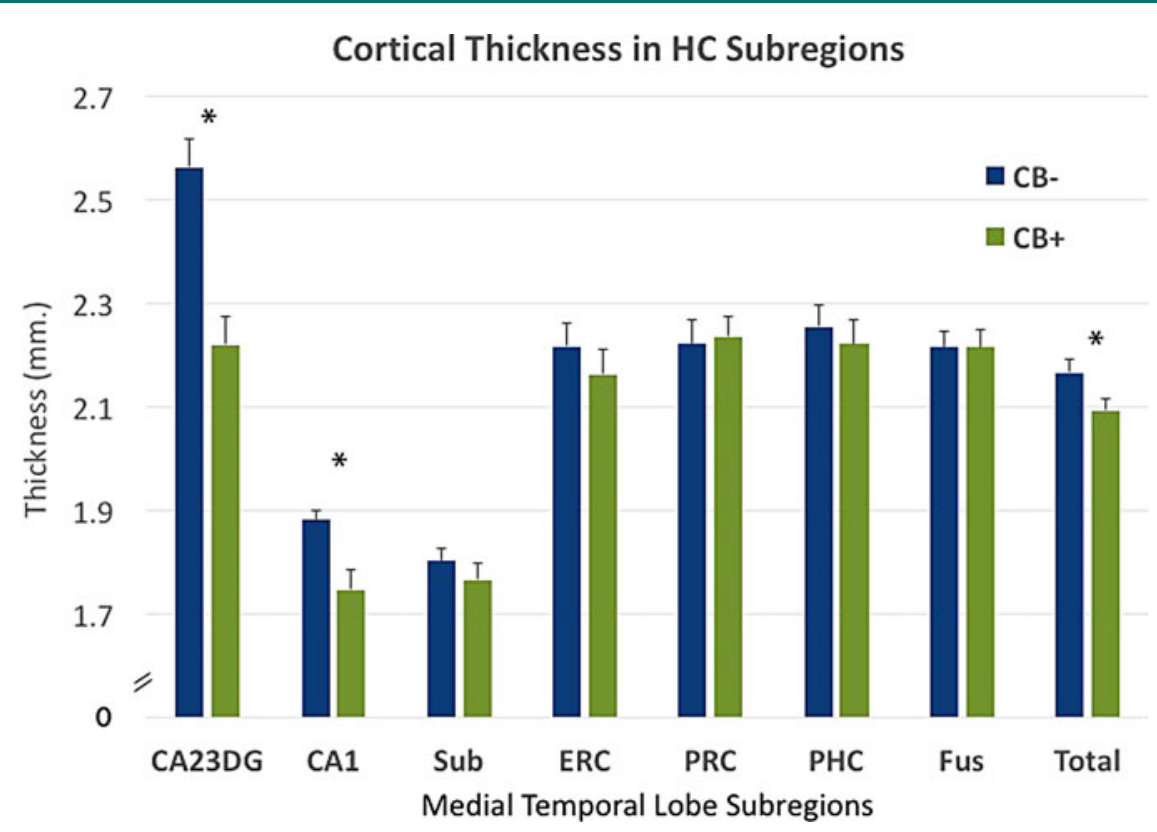

FIG. 3. Subregional cortical thickness in individual subregions for $\mathrm{CB}+$ and $\mathrm{CB}$ - groups. $\mathrm{CB}+$ subjects showed thinner cortex in subfields $C A 1[F(1,42)=9.96, p=0.003 ; E S=0.98]$ and $C A 23 D G[F(1,42)=23.17, p<0.0001$; $E S=1.49]$ and thinner hippocampus averaged over all subregions $[F(1,42)=8.49, p=0.006 ; E S=0.90]$. Group averages in subregional thickness are displayed with standard error bars. ${ }^{*} p<0.05$. ES, effect size. 


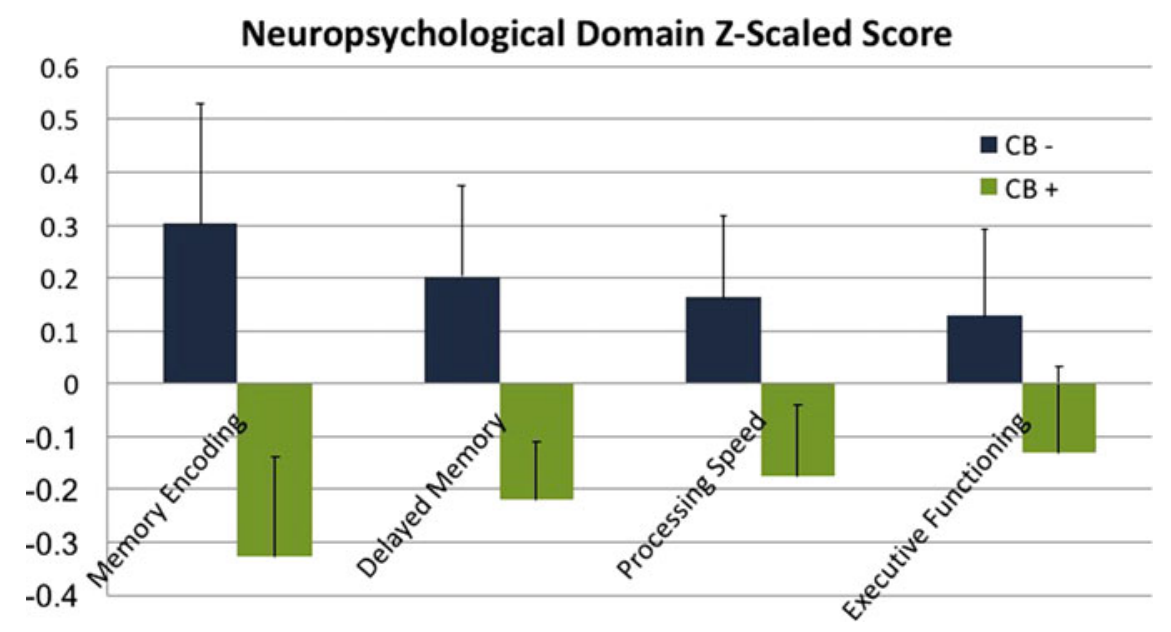

FIG. 4. Neuropsychological domain scores, Z-scaled for $\mathrm{CB}+$ and $\mathrm{CB}$ - groups. Domains were created using the following tests within each domain: Memory Encoding (Buschke-Fuld selective reminding test, consistent long-term retrieval; Wechsler Memory Scale-II, Logical Memory I and Verbal Paired Associates I), Delayed Memory (Wechsler Memory Scale: Logical Memory II and Verbal Paired Associates II; Rey-Osterrieth Complex Figure, Delayed Recall; Buschke-Fuld Selective Reminding Test, Delayed Recall), Processing Speed (Trailmaking Test, Part A; Stroop Test, Word Reading Speed; Wechsler Adult Intelligence Scale-III Digit Symbol), and Executive Functioning (Trailmaking Test Part B; Verbal Fluency FAS and Animal Naming tests; Stroop Test, Interference). Group averages and standard errors are displayed for all neuropsychological test domains. Differences between the groups were not significant, however, $C B+$ group averages were less than $C B$ - averages across all domains.

driving morphological differences between groups), CA1 and CA23DG thickness were still significantly lower in $\mathrm{CB}+$ subjects [CA1: $\mathrm{F}(1,35)=9.30, p=0.004$, $\mathrm{S}=1.03$; CA23DG: $\mathrm{F}(1,35)=23.95, p<0.0001, \mathrm{ES}=$ 1.65]. The two groups did not differ in SES either in early childhood or adulthood.

Additionally, although "Lifetime Alcohol Use" was not significantly different between the two groups $[t(48)=0.54, p=0.6]$, group models were run an additional time with this variable added as an covariate to test whether differences in alcohol use patterns were driving group differences. However, the pattern of significant differences in subregional cortical thickness between groups remained unchanged [CA23DG $[\mathrm{F}(1,41)=$ 25.32, $p<0.0001 ; \mathrm{ES}=1.37$ and $\mathrm{CA} 1[\mathrm{~F}(1,41)=9.67$, $p=0.003 ; \mathrm{ES}=1.05]$. In contrast, there were no group differences in the control parietal lobe region between the two groups $[F(1,41)=0.45, p=0.51 ; E S=0.21]$. No relationship between age of onset of cannabis use or lifetime cannabis use was found with thickness metrics. Differences between groups were not statistically significant across any neuropsychological measures [Memory Encoding
Domain: $\mathrm{F}(1,42)=0.90, \quad p=0.35, \quad \mathrm{ES}=0.29 ; \quad$ Delayed Memory Domain: $\mathrm{F}(1,42)=0.94, p=0.34$, ES $=0.30$; Processing Speed Domain: $\mathrm{F}(1,42)=1.33, p=0.26, \mathrm{ES}=0.36$; Executive Function Domain: $\mathrm{F}(1,42)=0.05, p=0.82$, $\mathrm{ES}=0.07]$. No neuropsychological domains showed a significant relationship with cortical thickness in any subregions. However, $\mathrm{CB}+$ group averages were lower than $\mathrm{CB}$ - group averages across all neuropsychological measures (Fig. 4).

\section{Discussion}

These results provide the first evidence of an association between early life CB use and later morphology changes in the medical temporal lobe, several decades after cessation of usage. Participants who reported heavy CB use in early life showed thinner cortex in hippocampal subregions CA1, 2, 3, and the DG. Morphological differences between groups were regionally specific to CA and DG regions and were not present in neocortical regions of the MTL, including entorhinal, perirhinal, and parahippocampal cortices. Additionally, cortical thickness in parietal cortex, a region relatively 
low in CB1 receptors but still subject to age-related changes, showed no differences between groups. These results underscore the persistent nature of adolescentinduced brain changes due to heavy $\mathrm{CB}$ use, and the rising need to understand how these changes interact with brain aging.

Our findings of thinner hippocampal cortex restricted to CA1, 2, 3 and the DG are relevant in relation to the functional impairment shown in chronic $\mathrm{CB}$ users during adolescence. Hippocampal subregions follow synaptic projections from the ERC through the DG, CA3, CA2, and then to Sub with each synaptic connection representing a specific function in the information processing pathway. ${ }^{57,58}$ Hippocampal subregions, CA1, CA3, and the DG, support the representation and encoding of novel information, allowing the $\mathrm{HC}$ to organize information and support short-term memory processes. ${ }^{59}$

In adolescent and early life $\mathrm{CB}$ users, memory impairment is one of the most frequent problems observed with persistent $\mathrm{CB}$ use, ${ }^{21}$ and it may be linked to specific structural alterations in CA3 and the DG. Although no differences in neuropsychiatric domain scores were found in the present study, lower scores in $\mathrm{CB}$ users were noted for every domain (Fig. 4); a larger sample size in future studies will help elucidate this relationship more fully.

Neuroimaging investigations on the structural effects of $\mathrm{CB}$ use on the brain have been inconsistent. ${ }^{32}$ Changes in gray or white matter density have been reported in different locations in frontal and parietal lobes without overlapping results across studies. ${ }^{60-62}$ These discrepancies might be due to heterogeneity in sample characteristics, individual differences in comorbid substance use, amount of consumption, or methodological differences in data processing. ${ }^{17,63}$

Changes in the HC/parahippocampal complex have often been reported ${ }^{33,62,64,65}$ and highlights the rationale behind the present investigation on the MTL, which was intended to investigate the relationship between early life CB use and late-life brain morphology. Although the precise mechanisms underlying the effects of $\mathrm{CB}$ on the $\mathrm{HC}$ are not fully understood, animal studies have shown that THC accumulates in neurons, ${ }^{66}$ with long-term exposure to THC resulting in neurotoxic changes in hippocampal microstructure, ${ }^{67}$ and there is particular concern regarding potential age-related interaction in the MTL, a brain area with high susceptibility to age-related morphology changes in late life. ${ }^{68}$ Adding to this concern, the fact that subjects in the present study had been rare or abstinent users for several decades suggests that CB-induced morphological changes from heavy adolescent exposure may have very long-term negative consequences.

Retrospective assessment of any drug use with no corroboration is challenging considering the life-long experiences and exposures among individual subjects. It is also noted that comparing parietal cortex, which is larger in size than the $\mathrm{HC}$, is not perfectly matched to the sensitivity of examining hippocampal subregions. Selection bias is another confound we recognize; one cannot know for certain if the differences in hippocampal atrophy between groups are due to pre-existing differences before $\mathrm{CB}$ use onset.

However, since the results held true after regression of the variables most likely to reflect baseline differences between groups (WTAR scores, gender, and cigarette use) as well as the specificity of results to CB1-rich brain regions, the findings presented in this study are not easily attributed to pre-existing group differences. Future studies should attempt to reproduce our CB-dependent effects in larger samples. Currently, the Adolescent Brain Cognitive Development study (https://abcdstudy.org) is prospectively following brain development with the largest long-term study of child brain development in the United States.

With increased usage, potency, and research indicating $\mathrm{CB}$ affects the $\mathrm{HC},{ }^{31}$ investigating the long-term effects of adolescent use in an aging population is essential for understanding the long-term consequences of heavy, early life $\mathrm{CB}$ exposure. Approximately $9 \%$ of persons who experiment with $\mathrm{CB}$ will become addicted. ${ }^{69}$ Our results provide evidence of neuroanatomical alterations in the hippocampi of ex-CB users and underscore the importance of assessing subregional hippocampal morphology. They also underscore the persistent nature of adolescentinduced brain changes due to $\mathrm{CB}$ use, and the rising need to understand how these changes interact with brain aging. Future studies should examine the effects of these morphological differences longitudinally to uncover the functional and behavioral implications of these brain differences.

\section{Acknowledgments}

The authors gratefully acknowledge the support of Jacqueline Martinez and colleagues with The Longevity Center at UCLA for help in recruitment and neuropsychological testing.

\section{Author Disclosure Statement}

No competing financial interests exist. 


\section{References}

1. United National Office on Drugs and Crime. World Drug Report. Executive summary: conclusions and policy implications. United Nations: Vienna, Austria, 2017.

2. United States Department of Health and Human Services. Results from the 2015 National Survey on Drug Use and Health: Summary of National Findings. Research Triangle Park, NC, 2016.

3. Bernheim A, Halfon O, Boutrel B. Controversies about the enhanced vulnerability of the adolescent brain to develop addiction. Front Pharmacol. 2013;4:118.

4. Crews F, He J, Hodge C. Adolescent cortical development: a critical period of vulnerability for addiction. Pharmacol Biochem Behav. 2007;86: 189-199.

5. Jager G, Ramsey NF. Long-term consequences of adolescent cannabis exposure on the development of cognition, brain structure and function: an overview of animal and human research. Curr Drug Abuse Rev. 2008;1: 114-123.

6. Scallet AC, Uemura E, Andrews A, et al. Morphometric studies of the rat hippocampus following chronic delta-9-tetrahydrocannabinol (THC). Brain Res. 1987;436:193-198.

7. Scallet AC. Neurotoxicology of cannabis and THC: a review of chronic exposure studies in animals. Pharmacol Biochem Behav. 1991;40:671676.

8. Burns HD, Van Laere K, Sanabria-Bohórquez S, et al. [18F] MK-9470, a positron emission tomography (PET) tracer for in vivo human PET brain imaging of the cannabinoid-1 receptor. Proc Natl Acad Sci U S A. 2007; 104:9800-9805.

9. Huxter JR, Miranda JA, Dias R. The hippocampal physiology of approaching middle-age: early indicators of change. Hippocampus. 2012 22:1923-1940.

10. Dornbush RL, Freedman AM. Chronic cannabis use: introduction. Ann N Y Acad Sci. 1976;282:vii-viii.

11. Hollister LE. Health aspects of cannabis. Pharmacol Rev. 1986;38:1-20.

12. Hollister LE. Health aspects of cannabis: revisited. Int J Neuropsychopharmacol. 1998;1:71-80.

13. Iversen L. Cannabis and the brain. Brain. 2003;126(Pt 6):1252-1270.

14. Ashtari $M$, Avants $B, C y c k o w s k i ~ L$, et al. Medial temporal structures and memory functions in adolescents with heavy cannabis use. J Psychiatr Res. 2011;45:1055-1066.

15. Yücel M, Lorenzetti V, Suo C, et al. Hippocampal harms, protection and recovery following regular cannabis use. Transl Psychiatry. 2016;6: e710-e710.

16. Volkow ND, Compton WM, Weiss SRB. Adverse health effects of marijuana use. N Engl J Med. 2014;371:878-879.

17. Lorenzetti V, Lubman DI, Whittle $S$, et al. Structural MRI findings in long-term cannabis users: what do we know? Subst Use Misuse. 2010; 45:1787-1808.

18. Solowij N. Cannabis and cognitive functioning. Cambridge University Press: Cambridge, 1998.

19. Solowij N, Stephens R, Roffman RA, et al. Does marijuana use cause longterm cognitive deficits? JAMA. 2002;287:2653-2654; author reply 2654.

20. Solowij N, Battisti R. The chronic effects of cannabis on memory in humans: a review. Curr Drug Abuse Rev. 2008;1:81-98.

21. Broyd SJ, van Hell $\mathrm{HH}$, Beale $\mathrm{C}$, et al. Acute and chronic effects of cannabinoids on human cognition-a systematic review. Biol Psychiatry. 2016;79:557-567.

22. Robinson J. Decades of drug use: data from the $60 \mathrm{~s}$ and, 70 's. Gallup: Washington, DC, 2002

23. Johansson $\mathrm{B}$, Zarit $\mathrm{SH}$, Berg S. Changes in cognitive functioning of the oldest old. J Gerontol. 1992:47:P75-P80.

24. Farmer ME, Kittner SJ, Rae DS, et al. Education and change in cognitive function. The Epidemiologic Catchment Area Study. Ann Epidemiol. 1995; $5: 1-7$

25. Schaie KW. The course of adult intellectual development. Am Psychol. 1994:49:304-313.

26. Grimby A, Berg S. Stressful life events and cognitive functioning in late life. Aging (Milano). 1995;7:35-39.

27. Hultsch DF, Hertzog C, Small BJ, et al. Short-term longitudinal change in cognitive performance in later life. Psychol Aging. 1992;7:571-584.

28. Carlson G, Wang Y, Alger BE. Endocannabinoids facilitate the induction of LTP in the hippocampus. Nat Neurosci. 2002;5:723-724.
29. Braak H, Braak E. Evolution of the neuropathology of Alzheimer's disease. Acta Neurol Scand Suppl. 1996;165:3-12.

30. Chye $Y$, Suo C, Yücel M, et al. Cannabis-related hippocampal volumetric abnormalities specific to subregions in dependent users. Psychopharmacology (Berl). 2017;234:2149-2157.

31. Lorenzetti V, Solowij N, Whittle S, et al. Gross morphological brain changes with chronic, heavy cannabis use. Br J Psychiatry. 2015;206: 77-78.

32. Battistella G, Fornari E, Annoni JM, et al. Long-term effects of cannabis on brain structure. Neuropsychopharmacology. 2014;39:2041-2048.

33. Yücel $M$, Solowij $N$, Respondek $C$, et al. Regional brain abnormalities associated with long-term heavy cannabis use. Arch Gen Psychiatry. 2008; 65:694-701.

34. Burggren AC, Zeineh MM, Ekstrom AD, et al. Reduced cortical thickness in hippocampal subregions among cognitively normal apolipoprotein E e4 carriers. Neuroimage. 2008;41:1177-1183.

35. Ekstrom AD, Bazih AJ, Suthana NA, et al. Advances in high-resolution imaging and computational unfolding of the human hippocampus. Neuroimage. 2009;47:42-49.

36. Donix M, Burggren AC, Suthana NA, et al. Family history of alzheimer's disease and hippocampal structure in healthy people. Am J Psychiatry. 2010;167:1399-1406.

37. Burggren AC, Renner $B$, Jones $M$, et al. Thickness in entorhinal and subicular cortex predicts episodic memory decline in mild cognitive impairment. Int J Alzheimers Dis. 2011;2011:956053.

38. Sicotte NL, Kern KC, Giesser BS, et al. Regional hippocampal atrophy in multiple sclerosis. Brain. 2008;131:1134-1141.

39. Varma VR, Tang $X$, Carlson MC. Hippocampal sub-regional shape and physical activity in older adults. Hippocampus. 2016;26:10511060.

40. Glass M, Dragunow M, Faull RL. Cannabinoid receptors in the human brain: a detailed anatomical and quantitative autoradiographic study in the fetal, neonatal and adult human brain. Neuroscience. 1997;77:299318.

41. Lockhart SN, DeCarli C. Structural imaging measures of brain aging Neuropsychol Rev. 2014;24:271-289.

42. Busquets Garcia A, Soria-Gomez E, Bellocchio L, et al. Cannabinoid receptor type-1: breaking the dogmas. F1000Research. 2016;5:990.

43. American Psychiatric Association. Diagnostic and statistical manual of mental disorders, 5th ed. American Psychiatric Publishing: Arlington, VA, 2013.

44. Gordon $\mathrm{H}$, Lee $\mathrm{P}$, Tamres L. The pituitary axis: behavioral correlates. In: Tarter R, Van Thiel D, Edwards K (eds.). Medical neuropsychology. Plenum Press: New York, pp. 159-196, 1988.

45. Beckwith B, Tucker D. Thyroid disorders. In: Tarter K, Van Thiel D, Edwards K (eds.). Medical neuropsychology. Plenum Press: New York, pp. 197-221, 1988

46. Ghoneim MM, Mewaldt SP. Benzodiazepines and human memory: a review. Anesthesiology. 1990;72:926-938.

47. Sobell LS, Sobell MB. Timeline Followback (TLFB) for alcohol. Addiction Research Foundation: Toronto, 1996.

48. Hollingshead A. Four-factor index of social status. Yale University: New Haven, CT, 1975.

49. Folstein MF, Folstein SE, McHugh PR. Mini-mental state: a practical method for grading the cognitive state of patients for the clinician. J Psychiatr Res. 1975;12:189-198.

50. Hamilton M. A rating scale for depression. J Neurol Neurosurg Psychiatry. 1960;23:56-62.

51. Weschler D. Weschler Test of Adult Reading. In: Weschler memory scale, Psychological Corporation, ed. 4th ed. Pearson: San Antonio, Texas, 2001.

52. Bonn-Miller MO, Zvolensky MJ. An evaluation of the nature of marijuana use and its motives among young adult active users. Am J Addict. 2009; 18:409-416.

53. Ercoli LM, Siddarth P, Kepe V, et al. Differential FDDNP PET patterns in nondemented middle-aged and older adults. Am J Geriatr Psychiatry. 2009;17:397-406.

54. Bilder RM, Goldman RS, Robinson D, et al. Neuropsychology of firstepisode schizophrenia: initial characterization and clinical correlates. Am J Psychiatry. 2000;157:549-559.

55. Donix M, Ercoli LM, Siddarth P, et al. Influence of Alzheimer disease family history and genetic risk on cognitive performance in healthy middle-aged and older people. Am J Geriatr Psychiatry. 2012;20:565573. 
56. Zeineh MM, Engel SA, Thompson PM, et al. Dynamics of the hippocampus during encoding and retrieval of face-name pairs. Science. 2003;299:577580 .

57. Amaral DG, Witter MP. The three-dimensional organization of the hippocampal formation: a review of anatomical data. Neuroscience. 1989;31: 571-591.

58. Gilbert PE, Brushfield AM. The role of the CA3 hippocampal subregion in spatial memory: a process oriented behavioral assessment. Prog Neuropsychopharmacol Biol Psychiatry. 2009;33:774-781.

59. Kesner RP. Behavioral functions of the CA3 subregion of the hippocampus. Learn Mem. 2007;14:771-781.

60. Churchwell JC, Lopez-Larson M, Yurgelun-Todd DA. Altered frontal cortical volume and decision making in adolescent cannabis users. Front Psychol. 2010;1:225.

61. Gruber SA, Silveri MM, Dahlgren MK, et al. Why so impulsive? White matter alterations are associated with impulsivity in chronic marijuana smokers. Exp Clin Psychopharmacol. 2011;19:231-242.

62. Matochik JA, Eldreth DA, Cadet JL, et al. Altered brain tissue composition in heavy marijuana users. Drug Alcohol Depend. 2005;77:23-30.

63. Batalla A, Bhattacharyya $S$, Yücel $M$, et al. Structural and functional imaging studies in chronic cannabis users: a systematic review of adolescent and adult findings. PLoS One Lu L, (ed.). 2013;8:e55821.

64. Demirakca T, Sartorius A, Ende G, et al. Diminished gray matter in the hippocampus of cannabis users: possible protective effects of cannabidiol. Drug Alcohol Depend. 2011;114:242-245.

65. Zalesky A, Solowij N, Yücel M, et al. Effect of long-term cannabis use on axonal fibre connectivity. Brain. 2012;135:2245-2255.

66. Monnet-Tschudi F, Hazekamp A, Perret N, et al. Delta-9-tetrahydrocannabinol accumulation, metabolism and cell-type-specific adverse effects in aggregating brain cell cultures. Toxicol Appl Pharmacol. 2008;228:8-16.

67. Landfield PW, Cadwallader LB, Vinsant S. Quantitative changes in hippocampal structure following long-term exposure to delta 9-tetrahydrocannabinol: possible mediation by glucocorticoid systems. Brain Res. 1988;443:47-62.

68. Thomann PA, Wüstenberg T, Nolte HM, et al. Hippocampal and entorhinal cortex volume decline in cognitively intact elderly. Psychiatry Res. 2013; 211:31-36.

69. Lopez-Quintero C, Pérez de los Cobos J, Hasin DS, et al. Probability and predictors of transition from first use to dependence on nicotine, alcohol, cannabis, and cocaine: results of the National Epidemiologic Survey on Alcohol and Related Conditions (NESARC). Drug Alcohol Depend. 2011; 115:120-130.

70. Heatherton TF, Kozlowski LT, Frecker RC et al. The Fagerström test for nicotine dependence: a revision of the Fagerström Tolerance Questionnaire. Br J Addict. 1991;86:1119-27.

71. Stephens RS, Roffman RA, Curtin L. Comparison of extended versus brief treatments for marijuana use. J Consult Clin Psychol. 2000;68:898-908.

Cite this article as: Burggren $A C$, Siddarth $P$, Mahmood $Z$, London $E$, Harrison TM, Merrill DA, Small GW, Bookheimer SY (2018) Subregional hippocampal thickness abnormalities in older adults with a history of heavy cannabis use, Cannabis and Cannabinoid Research 3:1, 242-251, DOI: 10.1089/can.2018.0035.

\section{Publish in Cannabis and Cannabinoid Research}

Cannabis and Cannabinoid Research
- Immediate, unrestricted online access

- Rigorous peer review

- Compliance with open access mandates

- Authors retain copyright

- Highly indexed

- Targeted email marketing 